\title{
Chlamydial Heat Shock Proteins and Disease Pathology: New Paradigms for Old Problems?
}

\author{
D. LaVerda, M.V. Kalayoglu, and G.I. Byrne* \\ Department of Medical Microbiology and Immunology, University of Wisconsin-Madison, \\ Madison, WI
}

\begin{abstract}
The mucosal pathogen Chlamydia trachomatis affects hundreds of millions of people worldwide and is a significant cause of sexually transmitted disease. Although most acute infections can be easily managed, complications often occur that can be especially severe in women. It has been proposed that increased exposure to conserved chlamydial antigens, such as through reinfection or persistent infection, results in chronic inflammation and tissue scarring and contributes to the pathogenesis of endometrial and fallopian tube damage. This immunopathologic damage is believed to be a principal cause of ectopic pregnancy and tubal factor infertility. The chlamydial heat shock protein $\mathrm{Hsp60}$, a homolog of Escherichia coli GroEL, has been identified as one protein capable of eliciting intense mononuclear inflammation. Furthermore, several studies have revealed a correlation between Hsp60 responses and the immunopathologic manifestations of human chlamydial disease. The role of additional antigens in the immunopathologic response to chlamydiae is currently undefined. A prime candidate, however, is the chlamydial GroES homolog Hsp10, which is genetically and physiologically linked to Hsp60. Recent studies provide data to suggest that immune reactivity to Hsp10 is significantly associated with tubal infertility in a chlamydiae-exposed population. Chlamydia pneumoniae is a more recently defined chlamydial species that has been implicated in a variety of ways with chronic disease processes, such as adult onset asthma and atherosclerosis. Evidence indicates that $\mathrm{Hsp} 60$ is present in human atheroma and may play a role in lesion development by direct activation of macrophages. Hsp60 causes the elaboration of inflammatory cytokines, the induction of metalloproteinase, and the oxidation of low density lipoprotein. Each of these events is directly associated with the progress of atherosclerosis. Thus, chlamydial heat shock proteins may function in at least two ways to promote chronic disease: first by direct antigenic stimulation and second as signal transducers that result in macrophage activation. These concepts in disease pathology are discussed in the context of chlamydial infections. Infect. Dis. Obstet. Gynecol. 7:64-71, 1999. 일 1999 Wiley-Liss, Inc.
\end{abstract}

KEY WORDS

Chlamydia; heat shock proteins; atherosclerosis; low-density lipoproteins

\section{BACKGROUND}

Chlamydiae are unique prokaryotic organisms. They not only are restricted to an obligate intracellular existence within the confines of a membranebound vesicle (inclusion) in the cytoplasm of susceptible host cells, but also they undergo morpho- logic, biochemical, and physiologic changes during the course of their intracellular existence. Productive chlamydial growth involves host cell invasion by the environmentally stable elementary body (EB) followed by differentiation to the metabolically active reticulate body (RB). Growth and rep-

Grant sponsor: Public Health Service; Grant Nos. AI19782, AI34617, and AI42790.

*Correspondence to: Gerald I. Byrne, University of Wisconsin, Department of Medical Microbiology and Immunology, 1300 University Avenue, Madison, WI 53706. E-mail: gibyrne@facstaff.wisc.edu 
lication of RB then proceeds by binary fission. The cycle is completed when the greatly expanded number of RBs differentiate back to $\mathrm{EB}$ and are released to infect new susceptible host cells. However, chlamydial growth as it exists during actual infections may include additional growth options that extend the definition of intracellular chlamydial development to choices beyond orderly transitions between EB and RB. Cell culture studies ${ }^{1-4}$ and observations in vivo ${ }^{5-8}$ demonstrate that chlamydial growth may manifest in a whole spectrum of interesting and novel ways. For example, Moulder et al. ${ }^{9}$ identified a cryptic form of chlamydial existence that may serve to perpetuate these organisms intracellularly in an unrecognizable form for extended periods of time. Similarly, intracellular RB may be induced to enter a nonreplicative, noninfectious stage of development that establishes a persistent, long-term relationship with the infected host cell that in some respects duplicates events that can be associated with chronic chlamydial infections. This nonproductive growth stage has been termed persistence ${ }^{1}$ and is characterized as a form of stressed growth, since stressresponse proteins such as the heat shock protein (hsp) Hsp60 are produced in greatly elevated amounts, compared with structural proteins, when chlamydiae are in this developmental state. The full range of stimuli that can cause chlamydiae to enter the persistent state are not definitively known, but host cell activation by immune regulated cytokines and growth at elevated $\left(39-42^{\circ} \mathrm{C}\right)$ temperatures appear to be two physiologically relevant stress-related conditions that can trigger persistence. In addition, persistence does not appear to be an irreversible process, since removal of inducing stimuli results in resumption of productive growth. In vivo evidence for chlamydial persistence has come from clinical conditions as diverse as arthritis, ${ }^{5}$ upper genital tract infections, ${ }^{6}$ trachoma, ${ }^{7}$ Alzheimer disease, ${ }^{8}$ and atherosclerosis. ${ }^{10}$ An important correlate of persistence and the disease process caused by chlamydiae involves the production of stress-response proteins during persistent growth. Chlamydial stress-response proteins have been associated with the pathologic consequences of chronic chlamydial diseases and provide the focal point for data and experimental systems reviewed here.

\section{CHLAMYDIA TRACHOMATIS, HEAT SHOCK PROTEINS, AND UPPER GENITAL TRACT INFECTIONS IN WOMEN}

Chlamydia trachomatis remains one of the most prevalent human microbial pathogens. This obligate intracellular bacterium is responsible for more than 4 million cases of sexually transmitted infections in the United States per year. ${ }^{11}$ Though the majority of these cases will be uncomplicated acute or asymptomatic infections for either men or women, about one in 10 women with inadequately treated or unrecognized cervicitis will progress to an upper genital tract infection such as salpingitis and pelvic inflammatory disease (PID). ${ }^{12}$ The consequences of these ascending complications can be severe. Chronic inflammation and subsequent fallopian tube scarring greatly increase the risk of ectopic pregnancy and tubal factor infertility (TFI). ${ }^{12}$ However, the manner by which endometrial and tubal damage accumulates in chlamydial upper genital tract disease has not been precisely defined. It is thought that antigens that are conserved among the various $C$. trachomatis serovars are important in eliciting these chronic inflammatory responses, since there is no evidence that immunopathologic potential is related to one or a subset of infecting chlamydial serovars. ${ }^{13,14}$ Repeated or continuous exposure to these antigens, such as through one or more reinfections or the development of persistent low-level chlamydial growth, may ultimately be the catalyst for immunopathologic development.

Precise identification of those chlamydial antigens that may participate in the immunopathologic response is an area of active investigation. Chlamydial hsps have been pursued as major players involved in human immune pathology as a result of several key studies that made associations between responses to the chlamydial GroEL homolog Hsp60 and the sequelae of upper genital tract disease including ectopic pregnancy, ${ }^{15}$ chronic pelvic pain, ${ }^{16,17}$ perihepatitis, ${ }^{18}$ and TFI. ${ }^{19-21}$ Antibody responses in particular have been used to show an increased frequency of seropositivity to chlamydial antigens among patients with immunopathologic sequelae when compared with appropriate controls. Though these studies may imply some level 
of connection, the causal mechanism by which the damage occurs remains poorly understood.

There have been several theories about how chlamydial hsps may elicit immune pathology. Work with animal models has identified Hsp60 as an antigen capable of eliciting profound inflammation characteristic of delayed-type hypersensitivity (D'TH). ${ }^{22,23}$ In a model of ocular chlamydial immunopathology, Morrison et al..$^{22}$ showed that purified Hsp60 triggered an immunopathologic response in sensitized animals that was histologically and clinically comparable to chronic chlamydial disease. Chlamydial lipopolysaccharide (LPS), a genusspecific antigen, and the major outer membrane protein (MOMP) did not elicit such responses ${ }^{24,25}$ in this model. Hsp60 has also been shown to elicit D'TH responses in genital tract tissue of sensitized animals, resulting in more severe disease. ${ }^{23}$ From these observations, a model of T-cell-mediated development of chlamydial immunopathology was proposed in which individuals who become sensitized by repeated or persistent exposure to Hsp60 developed a chronic mononuclear inflammation resulting in scarring and subsequent tissue damage.

Fine specificity analysis of the epitopes recognized by the immune response of women with severe upper genital tract disease led to the proposal that an autoimmune etiology of immunopathologic damage may be at work. Witkin et al. ${ }^{26}$ showed that $T$ cells from four out of 10 patients with recurrent salpingitis reacted to a peptide from a conserved region of Hsp60, while neither patients with first-episode salpingitis nor healthy controls recognized the cross-reactive epitope. Further research has shown that patients with advanced upper genital tract disease ${ }^{16}$ and sequelae ${ }^{15,27}$ have antibodies to certain epitopes on chlamydial Hsp60 that could cross-react with epitopes on the human homologue of Hsp60. Since chlamydial Hsps share significant homology with mammalian homologues, ${ }^{22,28}$ chronic or repeated exposure to these antigens may break immunological tolerance and lead to tissue damage.

Alternatively, an alteration of the local immune response to chlamydial hsps may promote immune pathology. Holland et al. ${ }^{29}$ have shown a depressed Th1 response among patients with trachoma. Since Th1 responses are noted to produce interferongamma, which inhibits chlamydial growth, perhaps this reduced capacity allows chlamydiae to escape eradication and persist at low levels at the site of developing immune pathology. Also, changes in inflammatory cytokines such as tumor necrosis factor- $\alpha$ and transforming growth factor- $\beta$ may adversely affect the progression of the local immune response. ${ }^{30-32}$ Whether by sensitization, epitopes recognized, or cytokines elaborated, the underlying theme to these theories seems to be that there is some fundamental difference in the immune response to chlamydial hsps between patients with and without immunopathology that is responsible for the development of damage. In any case, none of the above is necessarily mutually exclusive, and multiple mechanisms of tissue damage may take effect during different stages of pathological development.

While we know best the potential for chlamydial Hsp60 to cause inflammation and to be associated with chronic disease sequelae, there may be additional conserved chlamydial antigens that contribute independently or synergistically to the development of tissue damage. Though Hsp60 is certainly a clear immunopathology-associated antigen, ${ }^{4}$ in general, little is known about the capacity of other chlamydial proteins to induce DTH or autoimmune responses. Reports on the immunogenicity of hsp antigens from other microbial pathogens in the context of human disease have provided insight to pursue a second putative immunopathologic antigen. The Mycobacterium leprae and Mycobacterium tuberculosis homologues of Hsp10, members of the GroES family of proteins, have been shown to be prominent ' $\mathrm{T}$-cell antigens and targets of serum antibody responses. ${ }^{33-36} \mathrm{My}-$ cobacterial Hsp10 induces T-cell-mediated hypersensitivity in infected individuals and sensitized animals. ${ }^{36-39}$ Since Hsp10 homologues are genetically and physiologically linked with Hsp60 homologues, the chlamydial Hsp10 became a prime candidate for investigation.

Until recently, the antigenicity of chlamydial Hsp10 had not been investigated mainly due to the lack of purified protein and suitable antibody reagents for analysis. We have cloned and purified the Hsp10 from the common genital tract infection-associated serovar $\mathrm{E}$ of $C$. trachomatis $^{40}$ and have employed it in a series of assays to evaluate its potential to be immunopathogenic. To accomplish this, we initiated an approach not unlike the early Hsp60 serological investigations. In our current re- 
TABLE I. Comparison of the frequency of seropositive individuals by group and subgroup

\begin{tabular}{|c|c|c|c|}
\hline \multirow[b]{2}{*}{ Group } & \multicolumn{3}{|c|}{ Significantly more women seropositive for ${ }^{a}$} \\
\hline & Hspl0 & Hsp60 & MOMP \\
\hline Acutely infected women, compared to uninfected controls & Yes & Yes & Yes \\
\hline Women with TFI, compared to uninfected controls & Yes & Yes & Yes \\
\hline Are more women with TFI seropositive than acutely infected women? & Yes & Yes & No \\
\hline \multicolumn{4}{|l|}{ For EB+ patients only, are more women with TFI seropositive than } \\
\hline acutely infected women? & Yes & No & No \\
\hline \multicolumn{4}{|l|}{ For EB- patients only, are more women with TFI seropositive than } \\
\hline acutely infected women? & No & No & No \\
\hline
\end{tabular}

${ }^{a}$ Comparison of the number of positive serological responses in each indicated group or subgroup. A patient is scored seropositive if that patient's antigen-specific ELISA absorbance is greater than the mean plus two standard deviations of the control uninfected population. Significant differences determined by Fisher's exact test.

search, we are investigating whether a serological correlation exists between Hsp10 exposure and the immune sequelae of TFI. We hypothesize that among patients with evidence of prior chlamydial infection, those that exhibit tubal immunopathology would be more likely to have an immune response to Hsp10 than women with simple acute infections or uninfected healthy controls.

We have been able to establish several basic parameters about the immune response to chlamydial Hsp10. First, chlamydial Hsp10 was identified for the first time as a target of the immune response made by women with prior chlamydial exposure. Both women with active infections and women with TFI recognized Hsp10 more frequently than healthy uninfected women (Table 1). Of more significance, those women with TFI recognized Hsp10 more frequently than the actively infected women. The same pattern is seen when comparing the amount of antigen-specific antibody present in the serum of these women ('Table 2). Thus, women with TFI recognize Hsp10 more often and to a greater degree than either actively infected women or healthy uninfected women. This may reflect increased exposure to Hsp10 through repeated or persistent chlamydial infection. An interesting observation was made when each group was subdivided on the basis of seroreactivity to whole chlamydiae, and EB+ subgroups were analyzed separately from EB- subgroups. The association of Hsp10 reactivity with TFI among the EB+ subgroup became more significant, while associations among the EB- subgroup became insignificantly different from controls. This may indicate that chlamydiae-specific rather than cross-reactive epitopes of $\mathrm{Hsp} 10$ are associated with TFI. Taken together, these findings support the hypothesis that immunological exposure to $C$. trachomatis hsps is associated with TFI and identifies $\mathrm{Hsp} 10$ as an antigen recognized by a significant proportion of women with TFI. As has been proposed for Hsp60, Hsp10 reactivity may also contribute to the immunopathologic manifestations of severe upper genital tract complications of chlamydial disease in women. This study also points out that further research is warranted to more precisely define the potential contribution of Hsp10 and other conserved chlamydial antigens to the immunopathologic process.

\section{CHLAMYDIA, HSP60, AND ATHEROSCLEROSIS}

Chlamydial Hsp60 has not only been associated with disease severity in chronic sequelae of C. trachomatis infections, but also has recently been localized to human atheromatous tissue ${ }^{10}$ and associated with the development of atherosclerosis and atherosclerotic disease by several important criteria. This is a significant observation since $C$. pneumoniae has been implicated as a possible cause of atherosclerosis and atheroma development by a variety of clinical and epidemiological studies. ${ }^{41} \mathrm{Kol}$ et al. ${ }^{10}$ reported that both chlamydial and human Hsp60 could cause induction of the proinflammatory cytokine tumor necrosis factor- $\alpha$ and matrix metalloproteinase, an enzyme key in the production of thrombi dislodged from atheromatous plaque. Chlamydial Hsp60 together with chlamydial LPS ${ }^{42,43}$ also have been shown to cause activation of human monocytes in ways that relate directly to atheroma development and progression. One of the hallmarks of atheroma development is the accumulation of foam cells in the intimal space. Foam cells are macrophages that have stored high 
TABLE 2. Comparison of the magnitude of response as indicated by the amount of antigen-specific serum lgG present by group and subgroup

\begin{tabular}{|c|c|c|c|}
\hline \multirow[b]{2}{*}{ Group } & \multicolumn{3}{|c|}{ Significantly greater serum antibody levels to ${ }^{a}$} \\
\hline & Hsplo & Hsp60 & MOMP \\
\hline Acutely infected women, compared to uninfected controls & Yes & Yes & Yes \\
\hline Women with TFI, compared to uninfected controls & Yes & Yes & Yes \\
\hline $\begin{array}{l}\text { Do women with TFI have a greater level of response than acutely } \\
\text { infected women? }\end{array}$ & Yes & Yes & No \\
\hline $\begin{array}{l}\text { For EB+ patients only, do women with TFI have a greater level of } \\
\text { response than acutely infected women? }\end{array}$ & Yes & No & No \\
\hline $\begin{array}{l}\text { For EB- patients only, do women with TFI have a greater level of } \\
\text { response than acutely infected women? }\end{array}$ & No & No & No \\
\hline
\end{tabular}

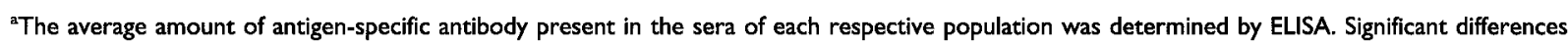
were determined by analysis of variance with Bonferroni posttests.

amounts of esterified cholesterol that can later be released to the extracellular milieu and contribute to the formation of the lipid core of the developing atherosclerotic lesion. Chlamydial LPS can cause foam cell development in the presence of lowdensity lipoprotein (LDL), which appears to occur in the absence of demonstrable LDL oxidative modification. ${ }^{43}$ Another event that is key to atheroma development is the oxidation of LDL and other lipid-containing moieties at the site of lesion progression. Low-density lipoprotein oxidation is dramatically accelerated in the presence of $C$. pneumoniae, and recent data demonstrate that chlamydial Hsp60 can substitute for the intact organism in promoting LDL oxidation. Interestingly, chlamydial Hsp10 was incapable of inducing oxidative changes that resulted when macrophages were exposed to Hsp60 in the presence of LDL. The interaction between chlamydial LPS, Hsp60, and known risk factors, such as elevated LDL, in the pathogenesis of atherosclerosis is summarized in Figure 1. It is reasonable to suppose that LDL oxidation precedes foam cell development, since large amounts of modified LDL can be taken up via scavenger receptors present on the surface of macrophages. ${ }^{44,45}$ This rationale is eminently sensible in light of the knowledge that the LDL receptor that functions in the uptake of unmodified LDL is tightly regulated in a negative feedback loop by excess intracellular cholesterol. ${ }^{46}$ However, in the presence of C. pneumoniae, chlamydial LPS, or chlamydial Hsp60, the sequence of events, at least in cell culture studies, suggest that LDL uptake occurs prior to LDL oxidation, suggesting that these two atherogenic events may not be directly linked in a way that requires LDL oxidation for foam cell development. This temporal scheme is illustrated in Figure 2.

\section{SUMMARY}

The intent of this report is to provide some perspective on the ways in which hsps may contribute to the disease process associated with various chlamydial infections. It is clear that severe pathologic consequences are most frequently associated with chronic rather than acute infections, and the potential for continuous elaboration of stress-response proteins in the face of a low grade, persistent infection would be predicted based on cell culture analyses. ${ }^{1}$ It is noteworthy that this prediction has been verified in several in vivo situations. ${ }^{5,8,10} \mathrm{~A}$ large body of data also has accumulated to suggest that chlamydial stress-response proteins play a role in the induction and development of diseases caused by chlamydiae (e.g., these proceedings). The continuous presence of chlamydial stressresponse proteins during chronic infection or as a result of repeated infections over time can influence the disease process in at least three ways. First, these proteins are antigenic. The immune responses elicited may directly result in tissue damage at the site of infection or may cause induction of cross-reactive immune responses involving host hsp homologues and thus the induction of autoimmunity (see above). These two possibilities should be further distinguishable by continued careful analysis of 'T- and B-cell epitopes involved in eliciting cell-mediated responses and antibody production. The third way in which chlamydial stress-response proteins may participate in the disease process is by direct activation of mononuclear phagocytes and other responsive cells. This inter- 


\section{A proposed role for $C$. pneumoniae infection in the pathogenesis of atherosclerosis}

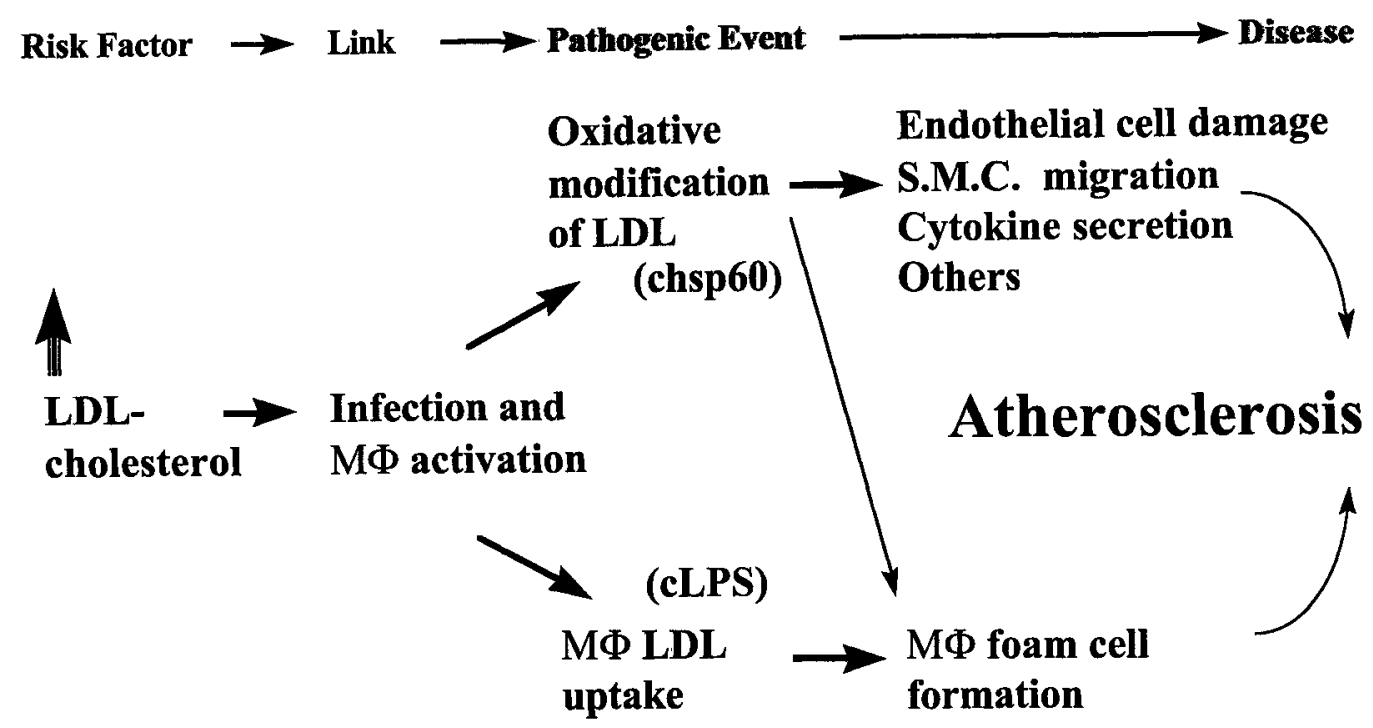

Fig. I. Chlamydia pneumoniae and atherosclerosis. Links between a known risk factor (elevated LDL), two possible chlamydial virulence factors (LPS and Hsp60), and the disease process (foam cell formation and oxidative-mediated tissue damage).

\section{A proposed role for $C$. pneumoniae infection in the pathogenesis of atherosclerosis}

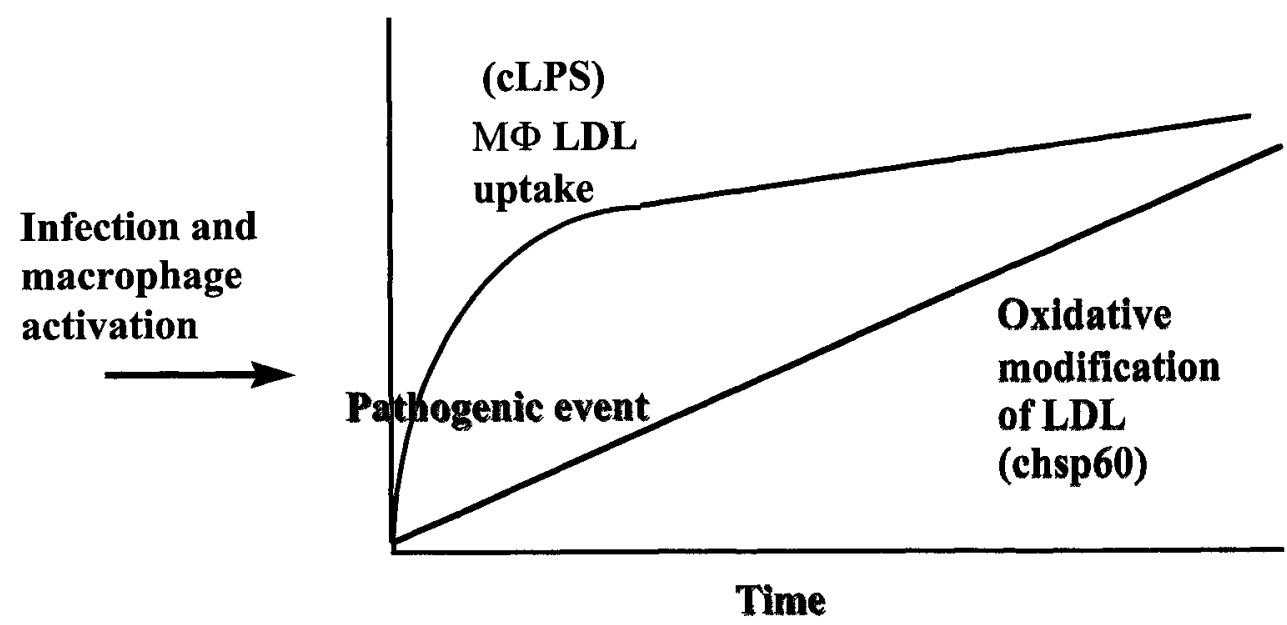

Fig. 2. Chlamydia pneumoniae and atherosclerosis. Temporal distinction between pathologic changes elicited by chlamydial LPS (foam cell formation) and Hsp60 (LDL oxidation).

esting possibility has been referred to as immune surveillance by Young and Elliot, ${ }^{47}$ and implies the presence of hsp receptors on cells that are capable of initiating signal transduction pathways. Indeed, Garduno et al. ${ }^{48}$ recently described an Hsp60- mediated invasion process for Legionella pneumophila entry into HeLa cells. In this context it may be significant that direct activation of macrophages by chlamydial $\mathrm{Hsp} 60$ appears to cause induction of matrix metalloproteinase ${ }^{10}$ and oxidation of LDL 
(described above). Additional disease promoting activities of chlamydial stress-response proteins will no doubt emerge from the study of a variety of chronic chlamydial infections as details are discovered concerning how these interesting proteins function in ways that promote disease.

\section{REFERENCES}

1. Beatty WL, Morrison RP, Byrne GI. Persistent chlamydiae: from cell culture to a paradigm for chlamydial parhogenesis. Microbiol Rev 1994;58:686-699.

2. Coles AM, Reynolds DJ, Harper A, Devitt A, Pearce JH. Low-nutrient induction of abnormal chlamydial development: a novel component of chlamydial pathogenesis? FEMS Microbiol Lett 1993;106:193-200.

3. Johnson FWA, Hobson D. The effect of penicillin on genital strains of Chlamydia trachomatis in tissue culture. J Antimicrob Chemother 1977;3:49-56.

4. Hatch TP. Competition between Chlamydia psittaci and L cells for host isoleucine pools: a limiting factor in chlamydial multiplication. Infect Immun 1975;12:211220.

5. Beutler AM, Whittum-Hudson JA, Nanagara R, Schumacher HR, Hudson AP. Intracellular location of inapparently infecting Chlamydia in synovial tissue from patients with Reiter's syndrome. Immunol Res 1994;13: 163-171.

6. Campbell LA, Patton DL, Moore DE, Cappuccio AL, Mueller BA, Wang S-P. Detection of Chlamydia trachomatis deoxyribonucleic acid in women with tubal infertility. Fertil Steril 1993;59:45-50.

7. Ward M, Bailey R, Lesley A, Kajbaf M, Robertson J, Mabey D. Persisting inapparent chlamydial infection in a trachoma endemic community in The Gambia. Scand J Infect Dis Suppl 1990;69:137-148.

8. Balin BJ, Gerard HC, Arking EJ, et al. Identification and localization of Chlamydia pneumoniae in the Alzheimer's brain. Med Microbiol Immunol 1998;187:23-42.

9. Moulder JW, Levy NJ, Schulman RP. Persistent infection of mouse fibroblasts (L cells) with Chlamydia psittaci: evidence for a cryptic chlamydial form. Infect Immun 1980;30:874-883.

10. Kol A, Sukhova GK, Lichtman AH, Libby P. Chlamydial heat shock protein 60 localizes in human atheroma and regulates macrophage tumor necrosis factor- and matrix metalloperoteinase expression. Circulation 1998; 98:300-307.

11. Centers for Disease Control and Prevention. Recommendations for the prevention and management of Chlamydia trachomatis infections, 1993. MMWR Morb Mortal Wkly Rep 1993;42:( RR-12)1-39.

12. Paavonen J, Lehtinen M. Chlamydial pelvic inflammatory disease. Hum Reprod Update 1996;2:519-529.

13. Beatty WL, Byrne GI, Morrison RP. Repeated and persistent infection with Chlamydia and the development of chronic inflammation and disease. Trends Microbiol 1994;2:94-98.
14. Brunham RC, Peeling RW. Chlamydia trachomatis antigens: Role in immunity and pathogenesis. Infect Agents Dis 1994;3:218-233.

15. Sziller I, Witkin SS, Ziegert M, Csapó Z, Ujházy A, Papp Z. Serological responses of patients with ectopic pregnancy to epitopes of the Chlamydia trachomatis 60 kDa heat shock protein. Hum Reprod 1998;13:10881093.

16. Domeika M, Domeika K, Paavonen J, Mårdh P-A, Witkin SS. Humoral immune response to conserved epitopes of Chlamydia trachomatis and human $60-\mathrm{kDa}$ heatshock protein in women with pelvic inflammatory disease. J Infect Dis 1998;177:714-719.

17. Eckert L, Hawes S, Wölner-Hanssen P, et al. Prevalence and correlates of antibody to chlamydial heat shock protein in women attending sexually transmitted disease clinics and women with confirmed pelvic inflammatory disease. J Infect Dis 1997;175:1453-1458.

18. Money D, Hawes S, Eschenbach D, et al. Antibodies to the chlamydial $60 \mathrm{kd}$ heat-shock protein are associated with laparoscopically confirmed perihepatitis. Am J Obstet Gynecol 1997;176:870-877.

19. Ault K, Statland B, Smith King M, Dozier D, Joachims $\mathrm{M}$, Gunter J. Antibodies to the chlamydial 60 kilodalton heat shock protein in women with tubal factor infertility. Infect Dis Obstet Gynecol 1999, in press.

20. Toye B, Laferriere C, Claman P, Jessamine P, Peeling R. Association between antibody to the chlamydial heat-shock protein and tubal infertility. J Infect Dis 1993;168:1236-1240.

21. Witkin SS, Jeremias J, Toth M, Ledger WJ. Cellmediated immune response to the recombinant $57 \mathrm{kDa}$ heat shock protein of Chlamydia trachomatis in women with salpingitis. J Infect Dis 1993;167:1379-1383.

22. Morrison RP, Lyng K, Caldwell HD. Chlamydial disease pathogenesis. Ocular hypersensitivity elicited by a genus-specific 57-kd protein. J Exp Med 1989;169:663 675.

23. Patton DL, Cosgrove-Sweeney YT, Kuo C-C. Demonstration of delayed hypersensitivity in Chlamydia trachomatis salpingitis in monkeys: A pathogenic mechanism of tubal damage. J Infect Dis 1994;169:680-683.

24. Taylor HR, Johnson SL, Schachter J, Caldwell HD, Prendergast RA. Pathogenesis of trachoma: the stimulus for inflammation. J Immunol 1987;138:3023-3027.

25. Watkins NG, Hadlow WJ, Moos AB, Caldwell HD. Ocular delayed hypersensitivity: a pathogenetic mechanism of chlamydial conjunctivitis in guinea pigs. Proc Natl Acad Sci USA 1986;83:7480-7484.

26. Witkin SS, Jeremias J, Toth M, Ledger WJ. Proliferative response to conserved epitopes of the Chlamydia trachomatis and human 60-kilodalton heat-shock proteins by lymphocytes from women with salpingitis. Am J Obstet Gynecol 1994;171:445-460.

27. Witkin SS, Askienazy-Elbhar M, Henry-Suchet J, Belaisch-Allart J, Tort-Grumbach J, Sarjdine K. Girculating antibodies to a conserved epitope of the Chlamydia trachomatis $60 \mathrm{kDa}$ heat shock protein (hsp60) in infertile couples and its relationship to antibodies to $C$. tracho- 
matis surface antigens and the Escherichia coli and human HSP60. Hum Reprod 1998;13:1175-1179.

28. Dickson R, Larsen B, Viitanen PV, et al. Cloning, expression, and purification of a functional nonacetylated mammalian mitochondrial chaperonin 10. J Biol Chem 1994;269:26858-26864.

29. Holland MJ, Bailey RL, Hayes LJ, Whittle HC, Mabey DC. Conjunctival scarring in trachoma is associated with depressed cell-mediated immune responses to chlamydial antigens. J Infect Dis 1993;168:1528-1531.

30. Bobo L, Novak N, Mkocha H, Vitale S, West S, Quinn TC. Evidence for a predominant proinflammatory conjunctival cytokine response in individuals with trachoma. Infect Immun 1996;64:3273-3279.

31. Rasmussen SJ, Eckmann L, Quayle AJ, et al. Secretion of proinflammatory cytokines by epithelial cells in response to Chlamydia infection suggests a central role for epithelial cells in chlamydial pathogenesis. J Clin Invest 1997;99:77-87.

32. Yi Y, Yang X, Brunham RC. Autoimmunity to heat shock protein 60 and antigen-specific production of interleukin-10. Infect Immun 1997;65:1669-1674.

33. Barnes PF, Mehra V, Rivoire B, et al. Immunoreactivity of a $10 \mathrm{kDa}$ antigen of Mycobacterium tuberculosis. J Immunol 1992;148:1835-1840.

34. Iangumaran S, Ramanathan S, Shankernarayan N, Ramu B, Muthukkarauppan V. Immunological profiles of leprosy patients and healthy family contacts toward $M$. leprae antigens. Int J Leprosy Mycobact Dis 1996;64: 6-14.

35. Kim J, Sette A, Rodda $S$, et al. Determinants of T cell reactivity to the Mycobacterium leprae GroES homologue. J Immunol 1997;159:335-343.

36. Mehra V, Bloom B, Bajardi AC, et al. A major $\mathrm{T}$ cell antigen of Mycobacterium leprae is a $10 \mathrm{kDa}$ heat shock cognate protein. J Exp Med 1992;175:275-284.

37. Launois P, Niang N'Diaye M, Cartel JL, et al. Fibro- nectin-binding antigen 85 and the 10 kilodalton GroESrelated heat shock protein are the predominant TH-1 response inducers in leprosy contacts. Infect Immun 1995;63:88-93.

38. Deshpande RG, Khan MB, Navalkar RG. Immunological evaluation of a 12 kilodalton protein of Mycobacterium tuberculosis by enzyme-linked immunosorbent assay. Tuber Lung Dis 1993;74:382-387.

39. Minden P, Houghton RA, Spear JR, Shinnick TM. A chemically synthesized peptide which elicits humoral and cellular immune responses to mycobacterial antigens. Infect Immun 1986;53:560-564.

40. LaVerda D, Byrne GI. Use of monoclonal antibodies to facilitate identification, cloning, and purification of Chlamydia trachomatis Hsp10. J Clin Microbiol 1997;35: 1209-1215.

41. Quinn T. Does Chlamydia pneumoniae cause coronary heart disease? Curr Opin Infect Dis 1998;11:301-307.

42. Kalayoglu M, Byrne G. Induction of macrophage foam cell formation by Chlamydia pneumoniae. J Infect Dis 1998; 177:725-729.

43. Kalayoglu MV, Byrne GI. A Chlamydia pneumoniae component that induces macrophage foam cell formation is chlamydial lipopolysaccharide. Infect Immun 1998;66: 5067-5072.

44. Ross R. The pathogenesis of atherosclerosis: a perspective for the 1990s. Nature 1993;362:801-809.

45. Berliner J, Heinecke J. The role of oxidized lipoproteins in atherogenesis. Free Radic Biol Med 1996;20:707-727.

46. Brown M, Goldstein J. Lipoprotein metabolism in the macrophage. Annu Rev Biochem 1983;52:223-261.

47. Young RA, Elliot TJ. Stress proteins, infection, and immune surveillance. Cell 1989;59:5-8.

48. Garduno RA, Garduno E, Hoffman PS. Surfaceassociated $\mathrm{Hsp} 60$ chaperonin of Legionella pneumophila mediates invasion in a HeLa cell model. Infect Immun 1998;66:4602-4610. 


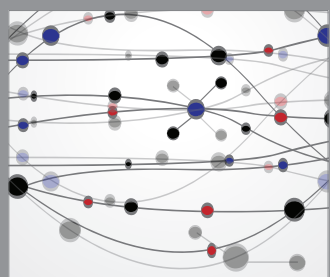

The Scientific World Journal
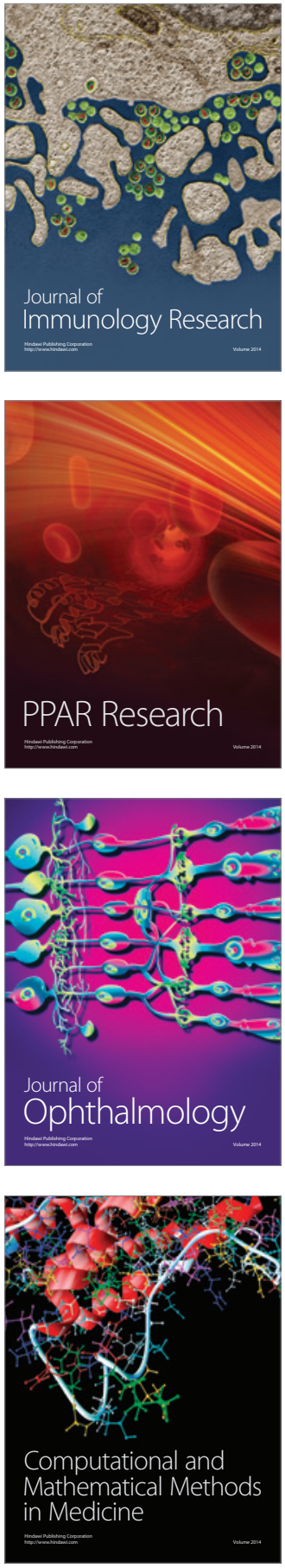

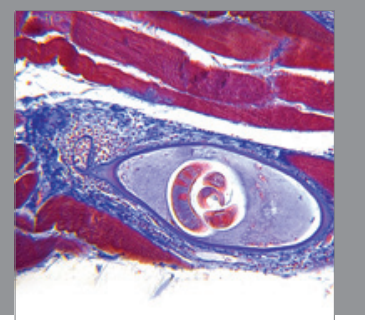

Gastroenterology

Research and Practice
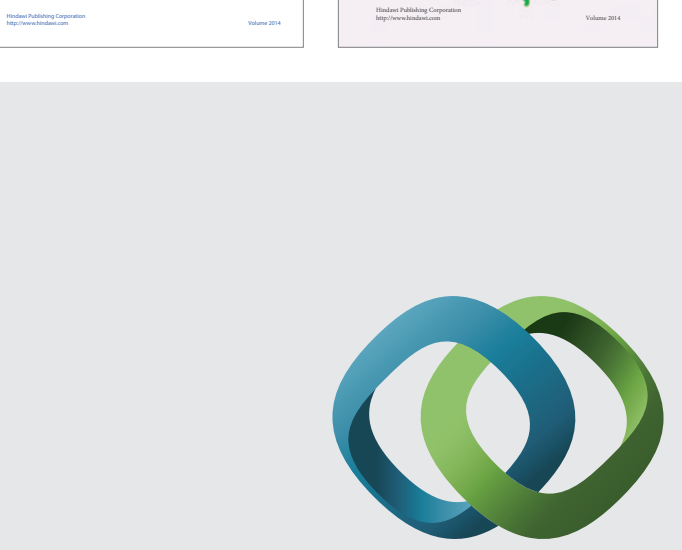

\section{Hindawi}

Submit your manuscripts at

http://www.hindawi.com
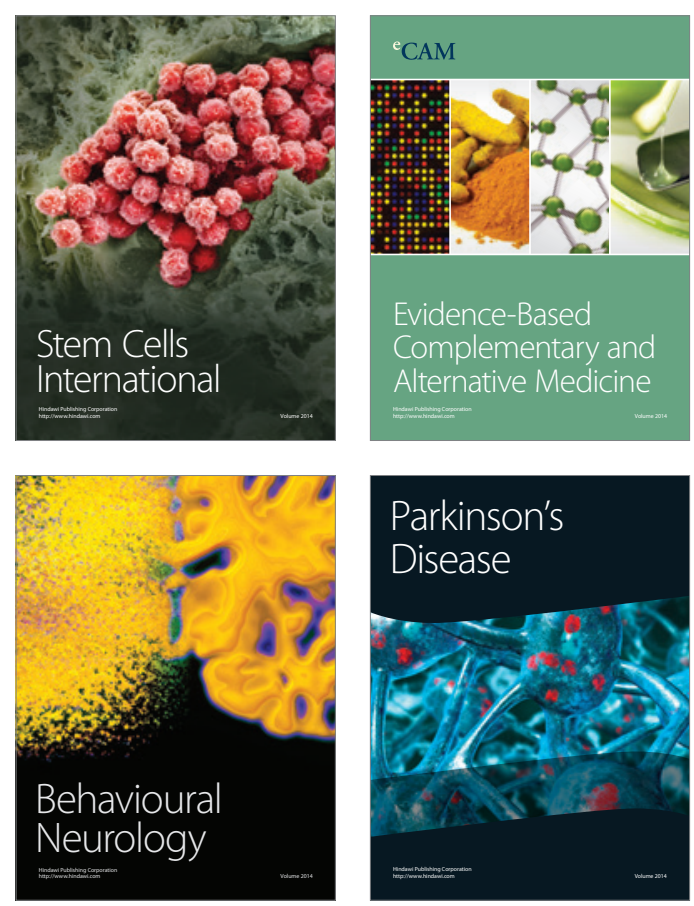

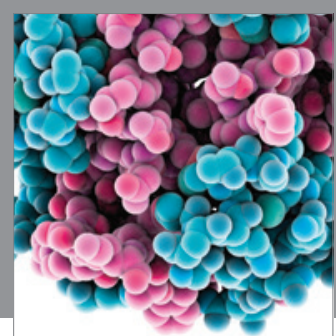

Journal of
Diabetes Research

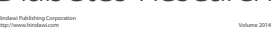

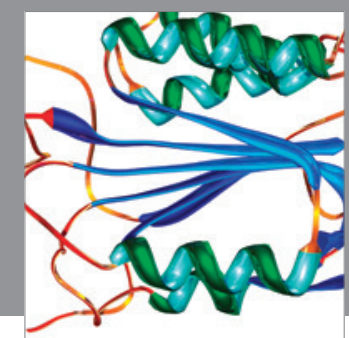

Disease Markers
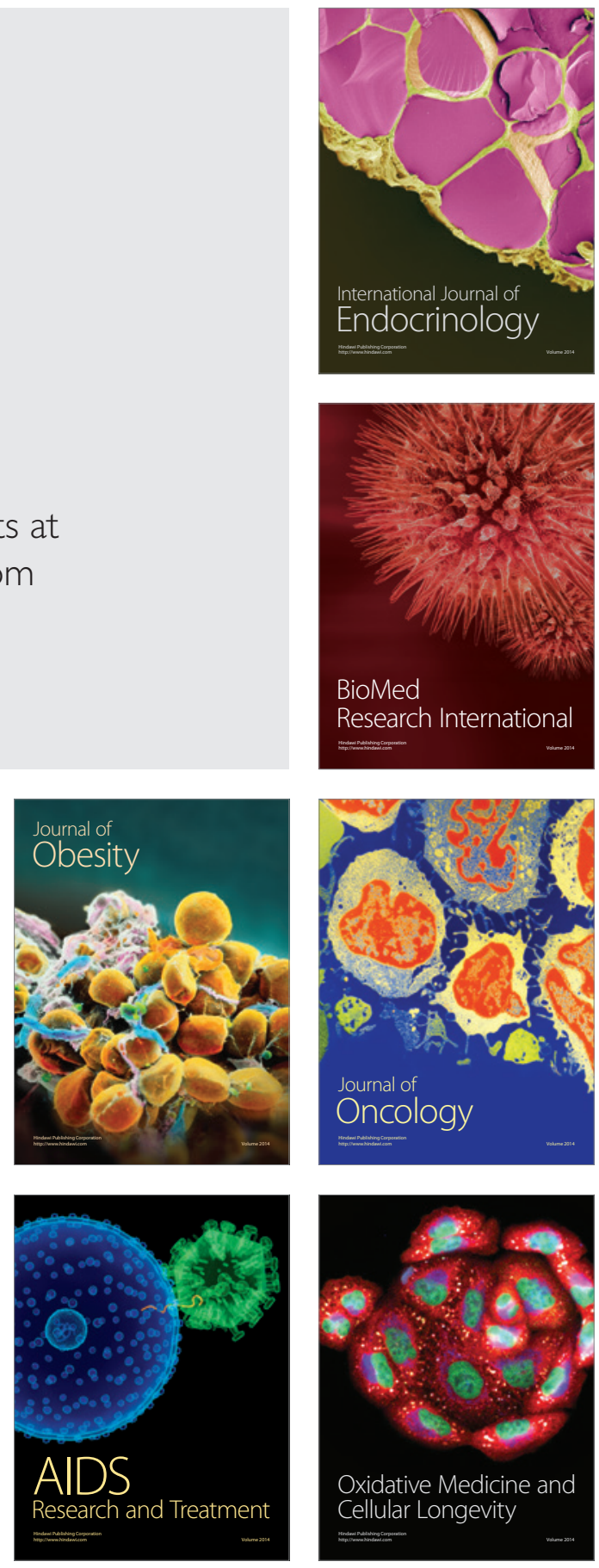